\title{
Towards intelligent structural design of buildings: A BIM-based solution
}

\author{
Tofigh Hamidavi, Sepehr Abrishami, M. Reza Hosseini
}

\section{Abstract}

Despite the unprecedented permeation of Building Information Modelling (BIM) and collaboration platforms, architects and structural engineers, for the most part, act as separate entities. That is, linking architectural models with that of structural engineers remains labour-intensive and cumbersome; structural engineers can generate few alternatives for any given architectural model. This paper is an attempt to address these problems. It provides an automated procedure, computational details and the configuration of toolsets in the form of a proof of concept (PoC) prototype that: binds architectural models with structural ones for tall buildings; automatically generates and updates alternatives for structural models, based on the input extracted from the architectural model; and provides engineers with an optimum design that fulfils the set criteria. The prototype is developed based on an initial need assessment study - to determine the requirements of practitioners. The practicality of the solution is assessed in a case project. The paper contributes to the field by presenting ones of the first solutions capable of automated generation of optimised structural design based on architectural models. Designed for tall buildings to incorporate immense complexity, the solution acts as a blueprint in developing similar systems for simpler buildings.

Keywords: digital engineering; integrated design; civil engineering; data management; collaboration; BIM level 3

\section{Introduction}

Effective design of buildings heavily relies on successful collaboration among all participants [1]. The growing complexity of modern architecture increases the challenges and compounds the problem of collaboration among architects and engineers [2]. In conventional design, architects and engineers are 
treated as two separate disciplines [3], with limited integration taking place among them, during early stages [4]. Architects begin with a conceptual design, provide the building shape and layout to meet functional and aesthetic requirements [5]. Thereafter, structural engineers establish the structural systems and skeleton of buildings, to meet safety, structural performance - and cost - criteria [6]. More often, structural design requirements are not considered adequately during architectural design, namely, the effects of architectural design on structural performance is overlooked [7]. Architects therefore end up with developing a design, which is difficult to be made structurally sound and infeasible to be built [8][9]. This fragmented arrangement has many other negative repercussions, too: information loss, duplication of data, inaccuracy, productivity loss, delays, cost overruns, increased litigation, and unsatisfactory deliverable quality [3].

To prevent such issues, architects and engineers require a collaborative system of working that automatically creates optimised design alternatives and meets both aesthetic requirements of architects and structural considerations of engineers alike. This requires a dynamic procedure that facilitates collaboration between the two teams - architects and engineers - during the whole design process, including early stages [10].

The extant literature, nevertheless, demonstrates that research on developing an automatic system to generate and optimise different options for structural design is inadequate [6]. Structural engineers heavily rely on intuitive knowledge and experience in manually generating conceptual designs and optimising them. This is an iterative and cumbersome process, during which engineers can consider few possible alternatives. The currently available methodologies like BIM have the potential to improve the structural design process by using the advantage of automation $[4,11,12]$. BIM is capable of enabling designers to generate and optimise different structural models through an automatic and parametric process [13]. Despite these capabilities, using BIM in facilitating structural design has remained an unexploited area $[3,14,15]$. The use of federated BIM models - along with common data environment (CDE) - facilitates bridging the gap between various disciplines [16]. This is however fraught with various 
problems $[17,18]$. Automated update of structural design based on architectural design change does not occur on projects. Moreover, BIM federated models are not equipped with an intelligent structural optimisation function $[15,19]]$.

This paper is an effort to address these issues of structural design processes, which still resemble a "loosely coupled system." [20] The main aim of this paper is therefore to bridge the gap between architects and structural engineers, reduce the time of design and provide a workable automated optimisation solution to integrate the operations of these - currently separate - disciplines. Such a solution remains much needed in the construction context, as argued by Leite [3] and Vilutiene [15]. Providing this solution to the field is hence the main contribution of this paper. The solution, as discussed next, is presented in the form of a proof of concept (PoC). This PoC integrates architectural and structural models, and facilitates automated intelligent structural model generation, exploration and optimisation, for any architectural model fed as the input.

\section{Contextual background}

Maintaining the flow of information among various disciplines and addressing competing and frequently conflicting interests are proven challenging $[5,21]$. The traditional supply chain in the construction industry displays a lack of integration of architects and structural engineers; their working procedures are fragmented and affected by silo mentality $[17,22]$. These two groups work in isolation and recognise responsibility for their own portion of the work [23]. Traditionally, the focus of architects is on the aesthetic aspects of buildings (building shape), while engineers give priority to the stability and performance of building structures $[8,15]$. These distinctions are the spur to serious problems: nonproductive activities with up to $15 \%$ of cost and time overruns; many change orders accounting for between $60 \%-90 \%$ of all variations, and inefficient communications that cause additional $5 \%-10 \%$ in cost and time overruns $[22,24]$. To lessen the detrimental impacts of such fragmentation and fill the gaps among these two disciplines, several remedial solutions are suggested in the literature, as discussed below. 


\subsection{Research on integration}

Many studies have recommended the use of technologies that facilitate collaboration among team members and provide a single shared interface, federated models and common data environment (CDE) $[25,26]$. Building Information Modelling (BIM) has emerged as an advanced methodology to provide the needed CDE and facilitate sharing data among various disciplines in design activities $[27,28]$. Though integrating disciplines has been a selling point of BIM, the gap between various disciplines remains an issue. There is evidence indicating that adopting BIM by itself has not resulted in bridging the gaps that conventionally existed among architects and engineers $[17,28]$. This has created a new stream of research with the goal being enhancing collaboration in BIM-enabled projects (see [28] for details), by various solutions. Moreover, though federated models create a common platform for various disciplines to share and integrate their models, there is still no computational - no intelligence - capability in federated models to translate changes of architectural details in updating structural models (see [16]). Emphasising the role of contractual arrangements, Olatunji [29] argued that the traditional legal structures that dominate construction projects - due to legal risks and liabilities associated with intellectual property - must be modified. As a response to that, Integrated Project Delivery (IPD) method has emerged with the objective of redefining project delivery into an integrated process, where all disciplines work with and see each other as members of a single unit [30]. IPD, though a relatively new and still evolving project delivery system, emphasises on the involvement of key participants, relationships, collaboration and the pursuit of mutual goals [22,31]. Nevertheless, evidence shows that few projects adopt IPD [32], due to cultural, financial, legal and technological barriers [22,32].

Despite the availability of BIM, IPD - and Common Data Environment (CDE) - the gap among architects and structural engineers remains a problem to be addressed [28]. The solution, as Merschbrock and Munkvold [33] and Kassem et al. [34] argue, relies on developing data exchange frameworks and tools. Developing new tools is recommended as an effective solution to facilitate integrating architecturalstructural collaboration [21]. 
Though the now-available methodologies and tools like federated models have noticeably improved the processes, the structural design of buildings is still an iterative process, laborious and inefficient. This is because, extant engineering software tools mainly provide structural solutions in integration with architectural designs; they do not compute or generate optimal design [13,35].

The structural design heavily relies on architectural design [8], that is, the behaviour of lateral load response - particularly for tall buildings - is highly affected by the shape of buildings [36]. Furthermore, construction involves an enormous financial cost. Therefore, design of a building requires structural engineers to consider not only safety and functionality factors, but design optimisation [37]. This is to fulfil important requirements like minimum structural cost, maximum structural efficiency and maximum usable floor area [35]. The ideal solution is an automated intelligent integrated procedure for linking architectural design with that of structural engineers, capable of generating alternatives for each submitted architectural design, as argued by Banihashemi et al. [13]. This is discussed next.

\subsection{Automated integration of design}

An automated design integration system must enable architects to incorporate structural design requirements at early stages of architectural design [38]. This system must be capable of facilitating structural design process too, where architectural models synchronise with structural ones; the system intelligently computes and translates any change of any submitted architectural model to alternations of the structural model [13]. Table 1 tabulates a brief summary of major studies on developing such a system.

Table 1. Major studies in the field (automated design integration)

\begin{tabular}{|l|l|l|l|}
\hline Reference & Focus & \multicolumn{1}{|c|}{ Objective(s) } & \multicolumn{1}{|c|}{ Limitation(s) } \\
\hline $\begin{array}{l}\text { Baldok and Shea } \\
{[39]}\end{array}$ & $\begin{array}{c}\text { Structural design } \\
\text { optimisation }\end{array}$ & $\begin{array}{l}\text { Reduce the structural } \\
\text { mass of the bracing }\end{array}$ & $\begin{array}{l}\text { Limited to bracing design for } \\
\text { steel frameworks }\end{array}$ \\
\cline { 1 - 3 } $\begin{array}{l}\text { Hofmeyer Delgado } \\
{[40]}\end{array}$ & $\begin{array}{l}\text { Performs structural } \\
\text { analysis and provide an } \\
\text { indication of structural } \\
\text { behaviour. }\end{array}$ & $\begin{array}{l}\text { Limited } \\
\text { collaboration with } \\
\text { architectural models }\end{array}$ \\
\hline
\end{tabular}




\begin{tabular}{|c|c|c|c|}
\hline $\begin{array}{l}\text { Mueller and } \\
\text { Ochsendorf [41] }\end{array}$ & & $\begin{array}{l}\text { Address the need to } \\
\text { consider both } \\
\text { quantitative } \\
\text { performance goals and } \\
\text { qualitative } \\
\text { requirements in } \\
\text { conceptual design }\end{array}$ & Only works with 2D frames \\
\hline Vermeulen [42] & & $\begin{array}{l}\text { Accelerate the process } \\
\text { of topology and size } \\
\text { optimisation }\end{array}$ & $\begin{array}{l}\text { Limited to collaboration with } \\
\text { architectural models }\end{array}$ \\
\hline $\begin{array}{l}\text { Richardson et al. } \\
\text { [43] }\end{array}$ & & $\begin{array}{l}\text { Provide a range of } \\
\text { optimal bracing } \\
\text { configurations based } \\
\text { on evolving structural } \\
\text { and architectural } \\
\text { requirements }\end{array}$ & $\begin{array}{l}\text { Limited to X-bracing and } \\
\text { topology optimisation }\end{array}$ \\
\hline Dutta et al. [44] & $\begin{array}{l}\text { Computer-Aided } \\
\text { Lift Planning } \\
\text { (CALP) systems }\end{array}$ & $\begin{array}{l}\text { Provide smart and } \\
\text { optimal solutions for } \\
\text { automatic crane lifting, } \\
\text { supported by } \\
\text { intelligent decision- } \\
\text { making and planning } \\
\text { algorithms along with } \\
\text { computer graphics and } \\
\text { simulation }\end{array}$ & $\begin{array}{ll}\text { - } & \text { Focused on lift } \\
\text { planning } \\
\text { - } & \text { Limited to structural } \\
\text { design process }\end{array}$ \\
\hline $\begin{array}{l}\text { Zayed and } \\
\text { Mohamed [45] }\end{array}$ & $\begin{array}{l}\text { Automatic } \\
\text { Climbing System } \\
\text { (ACS) }\end{array}$ & $\begin{array}{l}\text { A formwork to climb in } \\
\text { various weather and } \\
\text { height conditions }\end{array}$ & $\begin{array}{l}\text { Focused on climbing systems } \\
\text { and limited contribution to } \\
\text { the structural design process }\end{array}$ \\
\hline Li et al. [46] & $\begin{array}{l}\text { Wind-induced } \\
\text { response analysis } \\
\text { and design } \\
\text { optimisation for } \\
\text { rectangular steel } \\
\text { tall buildings }\end{array}$ & $\begin{array}{l}\text { Provide automated } \\
\text { optimised design } \\
\text { (minimum cost) }\end{array}$ & $\begin{array}{l}\text { Limited to architectural } \\
\text { models }\end{array}$ \\
\hline Chunyu and Li [47] & $\begin{array}{l}\text { Generation of } \\
\text { layout of high- } \\
\text { rise building in } \\
\text { urban landscape } \\
\text { design }\end{array}$ & $\begin{array}{l}\text { Automated generation } \\
\text { of layout of high-rise } \\
\text { buildings in urban } \\
\text { landscape design }\end{array}$ & $\begin{array}{l}\text { Limited to external elevation } \\
\text { of high-rise buildings in } \\
\text { urban landscape design }\end{array}$ \\
\hline $\begin{array}{l}\text { Wang and Mahin } \\
\text { [48] }\end{array}$ & $\begin{array}{l}\text { Automated } \\
\text { design and } \\
\text { optimisation for } \\
\text { seismic analysis }\end{array}$ & $\begin{array}{l}\text { Performance Based } \\
\text { Earthquake } \\
\text { Engineering (PBEE): an } \\
\text { automated tool that } \\
\text { incorporates an } \\
\text { optimisation engine } \\
\text { and structural analysis } \\
\text { software }\end{array}$ & $\begin{array}{l}\text { - Limited in } \\
\text { collaboration with } \\
\text { architectural models } \\
\text { - Focused on } \\
\text { automatic design } \\
\text { and optimisation of } \\
\text { seismic analysis }\end{array}$ \\
\hline Shahin [49] & $\begin{array}{l}\text { Adaptive building } \\
\text { envelopes for }\end{array}$ & $\begin{array}{l}\text { Control physical } \\
\text { environmental factors } \\
\text { (heat, light, sounds) }\end{array}$ & $\begin{array}{ll}\text { - } & \text { Focused on energy } \\
\text { performance }\end{array}$ \\
\hline
\end{tabular}




\begin{tabular}{|l|l|l|l|}
\hline $\begin{array}{l}\text { energy } \\
\text { performance }\end{array}$ & $\begin{array}{l}\text { Limited contribution } \\
\text { to the structural } \\
\text { design process }\end{array}$ \\
\hline
\end{tabular}

Apart from the studies included in Table 1, there exist some studies that focus on practical applications of architectural and structural synergy [50] and evolutionary structural optimisation [51]. One can also find several studies that try to use structural topology optimisation methods for generating optimal structural design, while maintaining the aesthetics and functionality of architectural design $[52,53]$. And there is another stream of research focused on the automatic integration of computational methods for topology optimisation $[54,55]$.

A review of the literature, however, reveals that these studies, for the most part focus on optimisation of structural design [6]; energy analysis [55-58]; integration between architecture-structural design to facilitate collaboration[59]; and interactive design process [60,61]. A review run on the literature does not spot any study that provides a cost-effective methodology and toolsets to link BIM, as a common tool for creating and storing data, with an automated structural design system. And industry reports do not refer to any toolset that extracts data from architectural models, runs experiments and provides an acceptable optimal structural design, all in an automated procedure. As discussed, the outcome of the review of the literature acknowledges the gap in the body of knowledge, namely, the reason for conducing this study. The design of the research study and the procedures followed are described next.

\section{Research methods}

\subsection{Research design}

Given that developing a PoC is the major task in hand, the research design adopts the systematic procedure - of creating a PoC - as suggested by the Queensland Government [66] for creating acceptable PoCs. Creating the PoC in this study is therefore based on a four-staged procedure: (1) research and requirement analysis; (2) system design (assumptions); (3) solution development; and (4) preliminary production assessment. 
Following the above approach; namely, moving from assessing the needs of the industry to developing solutions and then testing the practicality of proposed solutions - through a case project - is deemed a methodologically acceptable practice in construction research. This is in view of the availability of studies that have adopted a similar procedure in developing PoCs $[12,13,67]$.

\subsection{Research context}

Modern tall structures are complex large-scale slender structures. The task of structural engineers in designing tall buildings is more complicated, compared against other types of buildings, given the combined effects of various sorts of lateral loads [62]. This paper targets tall buildings, to capture maximum complexity in developing the solution. The application of the developed PoC, hence, can be extended to the structural design of simpler buildings like residential and commercial ones, therefore, the PoC can be a blueprint for developing similar solutions for infrastructure projects.

The nature of wind load is considered as a critical factor that controls the design of tall buildings [63]. Many researches stated that the structural optimisation of a tall building is greatly influenced by wind load [64][65][66][67]. Besides, for tall buildings, the shape of the building plays a key role in controlling the effect of the wind load [68]. The above facts justify the emphasis on wind load in calculations and design of the PoC in this study.

\subsection{Case project selection}

In order to assess the practicality and the potential performance of the proposed solution, Gherkin Tower is chosen as a case project to demonstrate how architects and engineers can use the proposed PoC. Gherkin Tower is chosen, because of its elongated, curved, shaft with a rounded end design that stands out against the conservative nature of many buildings in London [69]. This innovative design is selected as the case project to demonstrate the workability and efficiency of the PoC prototype in designing complex and creative designs. Furthermore, the unique shape of the Tower required ARUP [70] structural engineers to work closely with Foster and Partners [71] architects to achieve an ambitious curved form for the tower. Therefore, the proposed PoC prototype demonstrates how one 
can automate the synergy between architects and structural engineers in a BIM based platform to reduce the design time. The Gherkin tower has two primary structures comprising the diagrid and the core. The diagrid is the main part of the structure, resists the lateral and gravity loads, and transfers it to the core section of the structure. Cantor Seinuk defines diagrid as a series of triangles that combine gravity and lateral support into one, making the building stiff, efficient and lighter, compared against a traditional high rise building $[72,73]$.

\section{From requirement analysis to solution assessment}

The four-staged procedure of developing the PoC, as discussed, is explained next (see Queensland Government [66] for details).

\subsection{Research and requirement analysis}

The research and requirements analysis phase relied on an online questionnaire, to provide a list of main issues and challenges within the industry that affect structural design, analysis and optimisation process; questions also focused on interoperability and collaboration between structural engineers and architects. Moreover, this questionnaire asked participants to provide suggestions for potential solutions that address these challenges. Open-ended questions were included for both these parts to capture any items beyond those included within the list of questions. It is noteworthy of mentioning that the survey questionnaire was not designed to identify the issues; it was rather an attempt towards validating the findings of the literature and spotting any item that was missing from the pool of items found in the literature.

The questionnaire was distributed among professionally accredited structural engineers of the Institution of Structural Engineers (IStructE), Institution of Civil Engineers (ICE) and the American Society of Civil Engineers (ASCE) in the UK and US. Before distributing the questionnaire to the industry, a pilot study was conducted with 30 academic staff and researchers at the University of Portsmouth to provide 
valuable feedback in improving the questionnaire. At the end of the pilot phase, 6 completed questionnaires were returned.

After applying the feedback, the modified version of the questionnaire was distributed among 378 professionally accredited structural engineers. Eventually, 105 completed questionnaires returned, representing a response rate of $27.7 \%$. The analysis of data demonstrated that participants are from three groups of IStructE (60\%), ICE (21\%) and ASCE (19\%), from which 57\% were expert in structural design and engineering with more than 10 years of experience in this area. Figure 1 indicates the results of the survey, where participants highlighted the most challenging tasks associated with structural design, analysis and optimisation process.



Figure 1: Areas in need of improvement based on responses to the questionnaire As inferred from Figure 1, interoperability with other disciplines, automatic design generation system and design optimisation are the main reported challenges. Three questions were also used to identify potential solutions that address the challenges as raised (see Figure 2).

As illustrated in Figure 2 , more than $61 \%$ of respondents stated that automatic design is a potential solution to the existing challenges of building design, analysis and optimisation process. This rate increased to $69 \%$ in response to the question that asked about the integration of automatic design in BIM platform as a potential solution. A different strategy was taken to analyse the responses to the third question. First, respondents were asked how familiar they were with the concept of Generative Design 
(GD). For the sake of brevity, interested readers are referred to $[74,75]$ for detailed discussions on the concept of GD.

Only the responses of respondents who were familiar with GD were considered for further analysis.

Results indicate (see Figure 2) that respondents agreed that integration of GD and BIM at the early stage of structural design would be a potential solution to solve the existing challenges in building design process and improve the interoperability between architects and structural engineers.

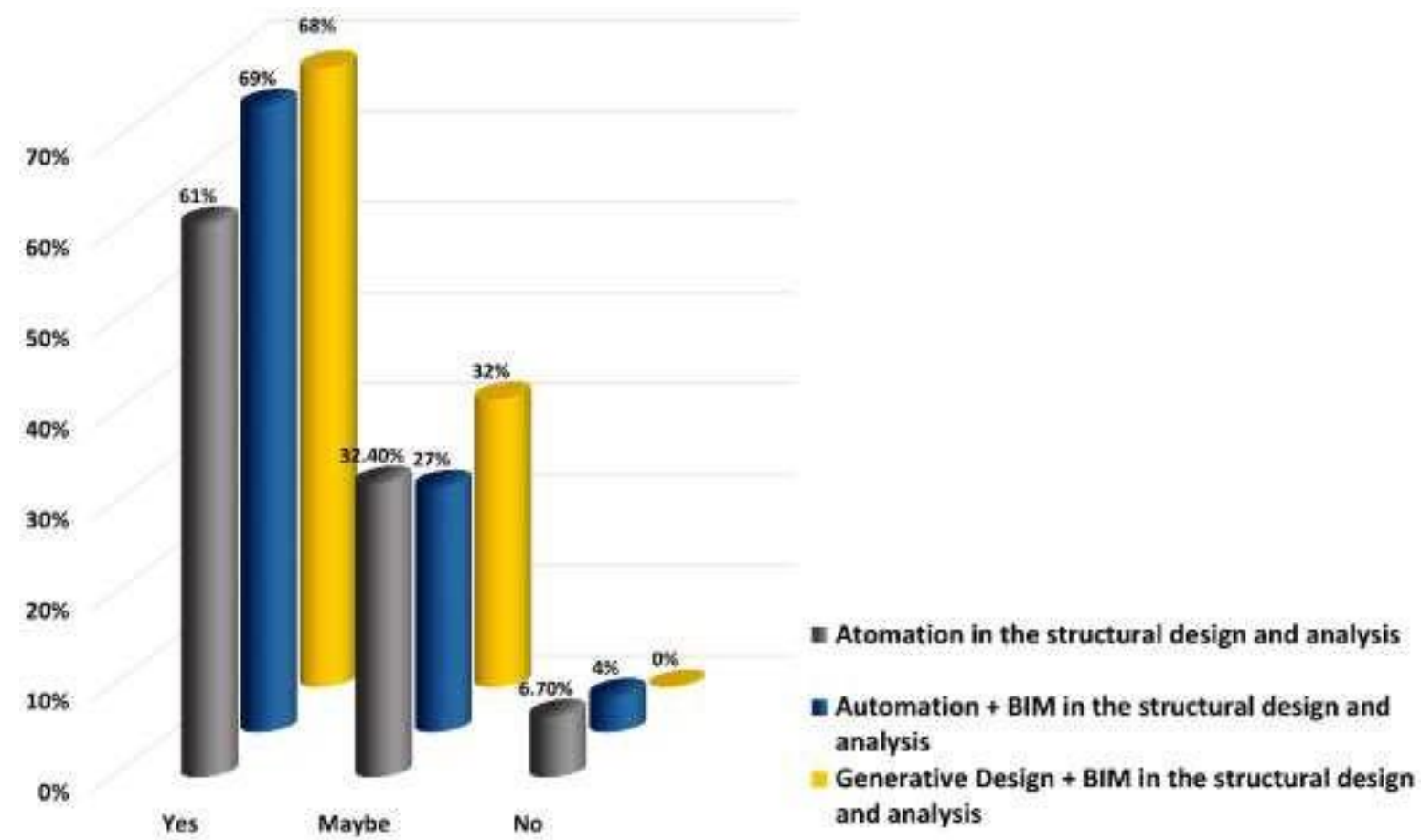

Figure 2: Potential solution to solve existing challenges

Thus, developing a state-of-the-art prototype to leverage the integration of GD in BIM platform in the current iterative process of building design - to improve interoperability - was considered as the overarching aim for designing the solution. 


\subsection{System design (assumptions)}

Figure 3 and the discussions that follow provide an account of the details of the tools, procedure, considerations and key assumptions in designing the solution.

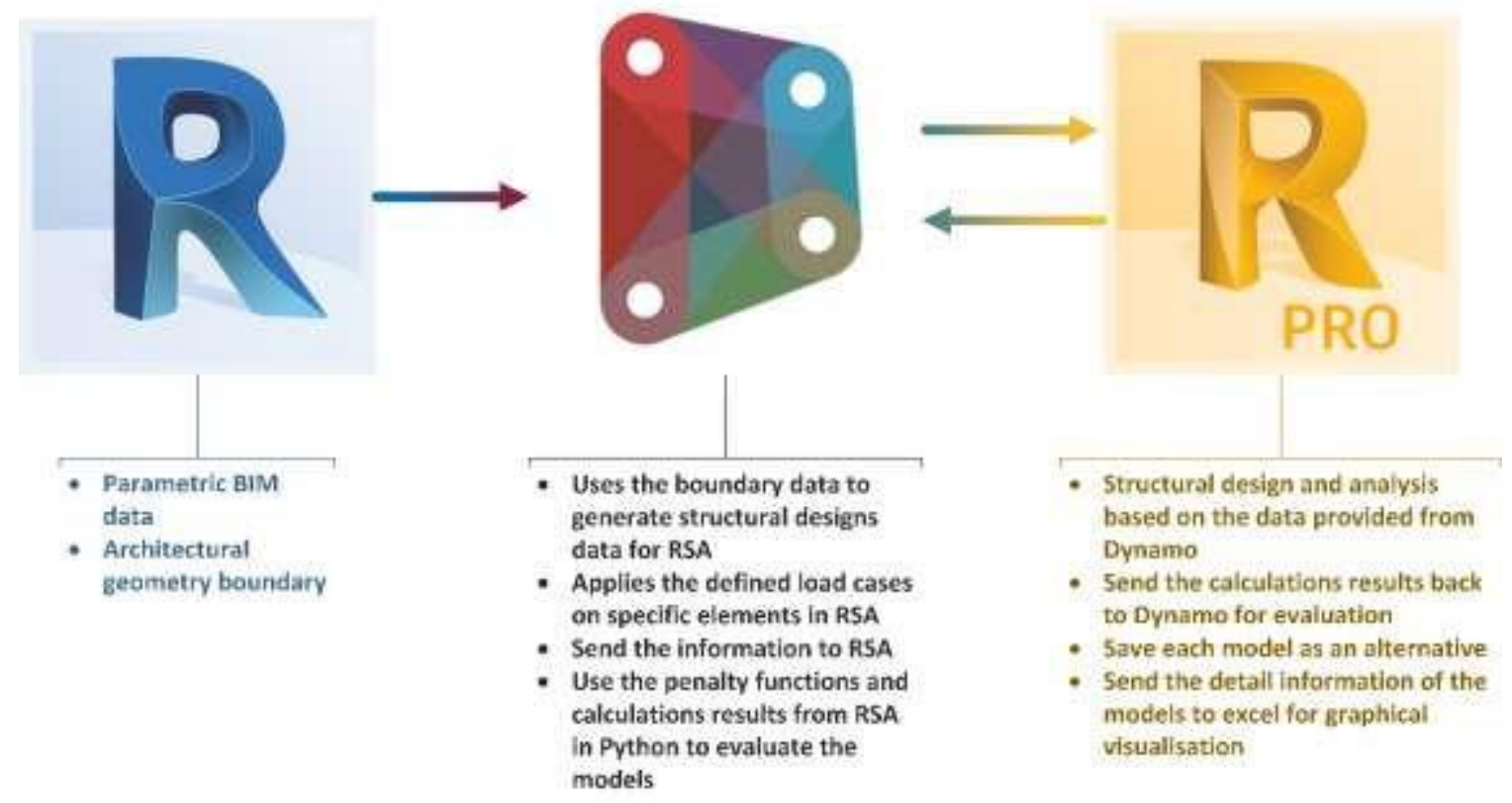

Figure 3: BIM tools and the procedure to develop the prototype (RSA: Robot Structural Analysis)

\subsubsection{Automatic synergy}

The integration between structural engineers and architects is a fundamental aspect, which requires new tools and methods to overcome technical challenges [76]. To establish the automated synergy needed, the study drew upon the capabilities of visual programming - to create the automated link between architectural and structural design procedures. In parametric BIM, visual programming interface can replace the conventional elaborate coding with visual small blocks, which work independently to perform certain tasks [77]. Visual programming enables designers to develop computer programs by manipulating visual block and linking them graphically rather than using coding this is much easier for users with no programming background [13].

Recent developments in building design technology offer new opportunity to use visual programming tools for designers. Chief among all available tools are Grasshopper $[78,79]$ and Dynamo [80]. Dynamo performs efficiently with Autodesk Revit (hereafter referred to as Revit) and extends the power of Revit 
by providing access to the Revit API (Application Programming Interface) [81]. In the designed process, Dynamo synchronises the parametric data of the architectural model into the structural design platform to design different alternative structural models [12]. The main advantage of this automatic synergy: all generated structural models are based on the boundary conditions the submitted architectural model; any change of the architectural model will update structural models - automatically.

As discussed, structural engineers need to reduce the demanding tasks related to the iterative processing of structural design. The proposed prototype is developed on a BIM-based platform to facilitate data exchange and create synergy between structural and architectural models. That is, BIM tools enable designers to use parametric data to model 3D geometric shapes [13]. Hence, the proposed toolset can generate alternative structural models using geometry parameters (from Revit) and rules (in Dynamo). This allows designers to automatically update structural models according to any change of architectural model parameters.

\subsubsection{Structural optimisation}

According to the results of the questionnaire, structural optimisation is the third challenging task of the structural design process (see Figure 1). Structural optimisation is a mathematical approach towards reducing the amount of material, consequently cost and simultaneously sustaining the applied loads [53]. Structural optimisation is generally demonstrated in the form of Equation 1 [82]:

$\{$ minimises/maximises $f(x, y)$ with respect to $x$ and $y$ subject to: $\{$ behavioral constraints on y design constraints on $x$ equilibrium constraints. Equation 1

Where:

$f(x, y)$ : Objective function, is used to classify the design and aims to either minimise or maximise the value. According to the aim of designer, this value varies; it can measure weight, displacement or stress. In this paper, $f(x, y)$ is an objective function (effect of wind) to be reduced by using different design variables and generate different structural models. 
$x$ : Design variable, represents the geometric properties of design and it can be altered during the optimisation process. The proposed prototype uses different $x$ variables as design variables to use in predefined functions and generate different structural models.

$y:$ State variable, is a function that defines (generates) the result of the structure for the specific $x$ value. The proposed prototype uses $y$ as a mathematical function to generate different structural models based on different $x$ variables.

Structural optimisation can be classified into three optimisation methods $[83,84]$, a description of which follows.

Shape optimisation: the shape of a structure is optimised without changing the topology; in this paper, the radius of each circle floor of the tower is considered as a design variable for shape optimisation.

Topology optimisation: the topology of a structure optimises the location of structural elements; in this paper the number of points at the circumference of floors determine the number and location of the diagrid of the tower.

Size optimisation: a typical size of a structure is optimised (for example, a thickness distribution of a beam or a plate); in this paper the parametric data of the Revit family is used to generate different cross sections for size optimisations purposes.

Topology optimisation is an effective method to facilitate the trade-off between architects' aesthetic criteria and engineers' engineering requirements. This method has been widely used in other fields, with applications spanning from mechanical to aerospace engineering $[85,86]$.

\subsection{Solution development}

The solution development started with creating a schematic process flowchart, to demonstrate the workflow, as illustrated in Figure 4. 


\subsubsection{Schematic process flowchart}

Figure 4 demonstrates a schematic process flowchart, focused on solving the existing challenges and addressing the requirements of the industry - as reflected on the responses submitted to the online questionnaire.

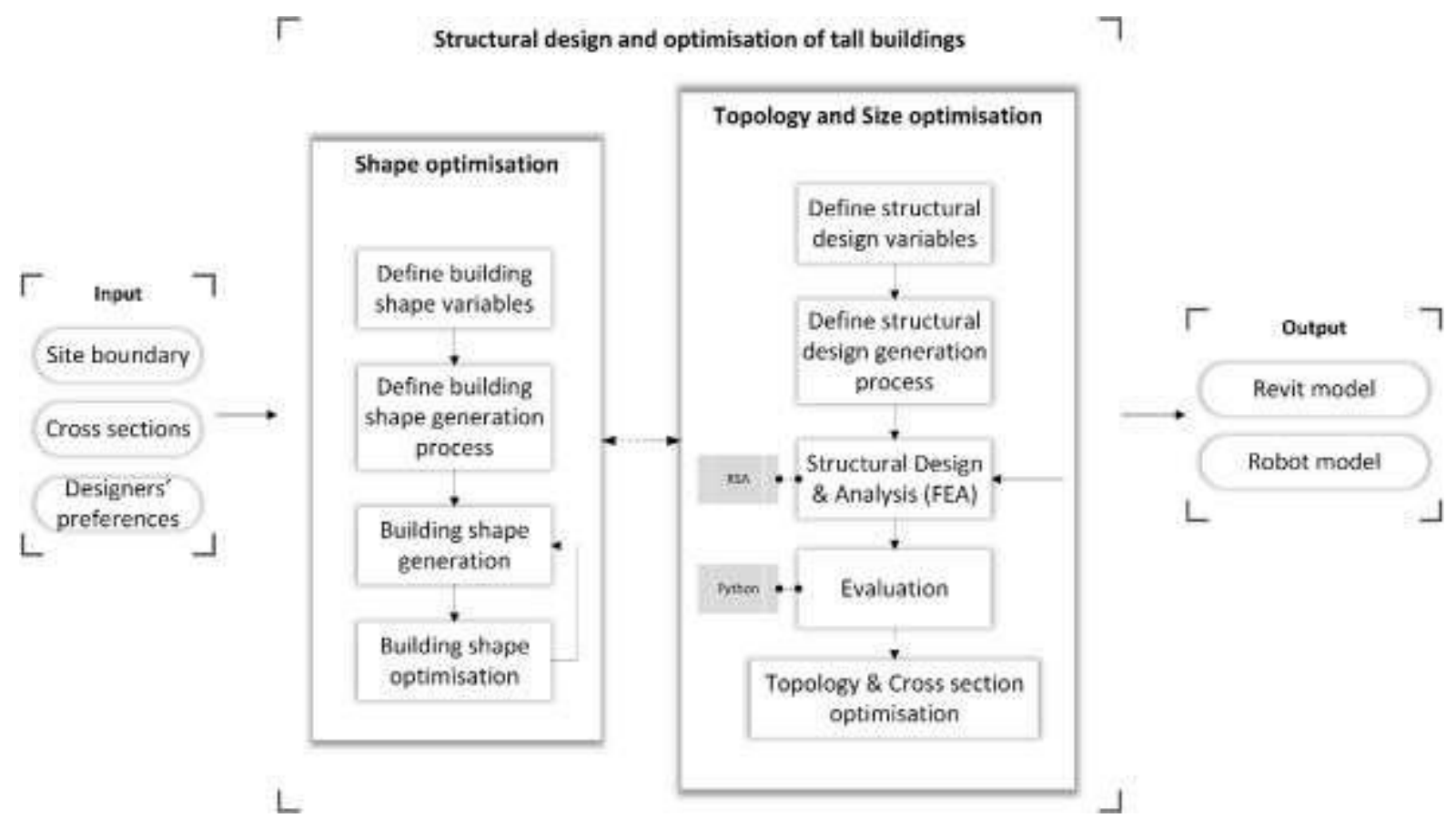

Figure 4: Structural design and optimisation of tall buildings flowchart

Three optimisation methods of shape, topology and size optimisation of the structural design, as discussed, were used; in a BIM-based platform to use the parametric data in Revit; in mathematical predefined functions in Dynamo to generate, analyse and optimise different options of structural models in RSA.

The procedure initiates with the structural shape generation and optimisation by defining parametric shape variables and mathematical functions to create structural geometric entities (see Figure 4). Thereafter, structural topology and size optimisation begins through a robust structural performance assessment process to generate different integrated options of structural designs during early stages. In this process, every set of shape variable in Dynamo mathematical functions defines a structural model in Revit and RSA. Hence, numerical variables and mathematical functions enable the designer to vary the structural shape and the structural topology of the building and optimise the structural elements size in 
an easier and quicker automatic process. As discussed, the aim of using topology optimisation in this paper is to reduce the gap between the two disciplines of architects and engineers during the design process.

\subsubsection{Input}

This section is about input data such as the site boundary and a list of various cross-sections and designers' preferences. Site boundaries are included to position the building in its accurate location and prevent the building footprint to go beyond the site boundary. Site boundary is utilised in the shape design and optimisation section; hence, structural design is in the exact location of the architectural model. Therefore, defining site boundary dictates the location of structural models.

Moreover, the input section of the prototype includes a list of various cross-sections to be used in structural design and optimisation section, to optimise the structure in terms of elements size optimisation. This enables designers to type the name of the cross sections in the relevant node to load the cross section in RSA and generate the structural model by using the cross section (see Figure 4).

Designers' preferences, as included among inputs, play a key role in defining mathematical functions and the whole process of the architectural-structural design and optimisation. These preferences influence the process of building shape generation, topology optimisation, cross-sections size and the code of structural analysis (Euro-Codes (EC), British Standards (BS) etc.), for structural evaluation purposes.

\subsubsection{Shape optimisation}

At this stage, designers define mathematical functions. This is to design the shape of the building by using building shape variables based on their preferences and input data, like site boundary, to generate and optimise the shape of the building parametrically (Figure 4). The visual programming tool (Dynamo) is used to define the mathematical functions and design the building shape generation process. This process uses site boundary and building shape variables information to generate different alternative building shapes structural models and optimise the shape of the building by varying the variables in an 
automatic process. This method enables designers to generate different structural shapes within the required site boundary and optimise the shape of the building designs by varying building shape variables, which are adjustable, based on designer's preferences.

\subsubsection{Structural design and optimisation}

According to Figure 4, structural topology and size optimisation process run after the shape optimisation process. That is, any change in the shape of the structural model due to the architectural site boundary will automatically affect the topology arrangements. This link between different stages of the prototype improves collaboration and integration between architects and engineers through an automated process, by using visual programming language tools (Dynamo). Like the shape optimisation stage, topology and size optimisation of structural design are based on structural design variables. Thereafter, by changing structural design variables, different alternative structural models with different topology arrangements and various elements cross-sections sizes are generated, automatically. These structural design alternatives are synchronised to architectural models, based on designers' (engineers') preferences. Therefore, any change and adjustment to the architectural model (boundary conditions) or engineers' preferences (topology arrangement and/or elements' cross-sections size) automatically updates the structural design and generates new models. By changing variables related to the building shape, topology and section size, the mathematical functions generate and analyse different building shapes and topology with various cross sections. The cross sections part provides different element sizes to generate alternative structural models with different cross section sizes (Figure 5). The number and 
type of cross sections depend on the designer's preferences. This enables engineers to use various cross sections from different codes like Euro-Codes (EC) and British Standards (BS).

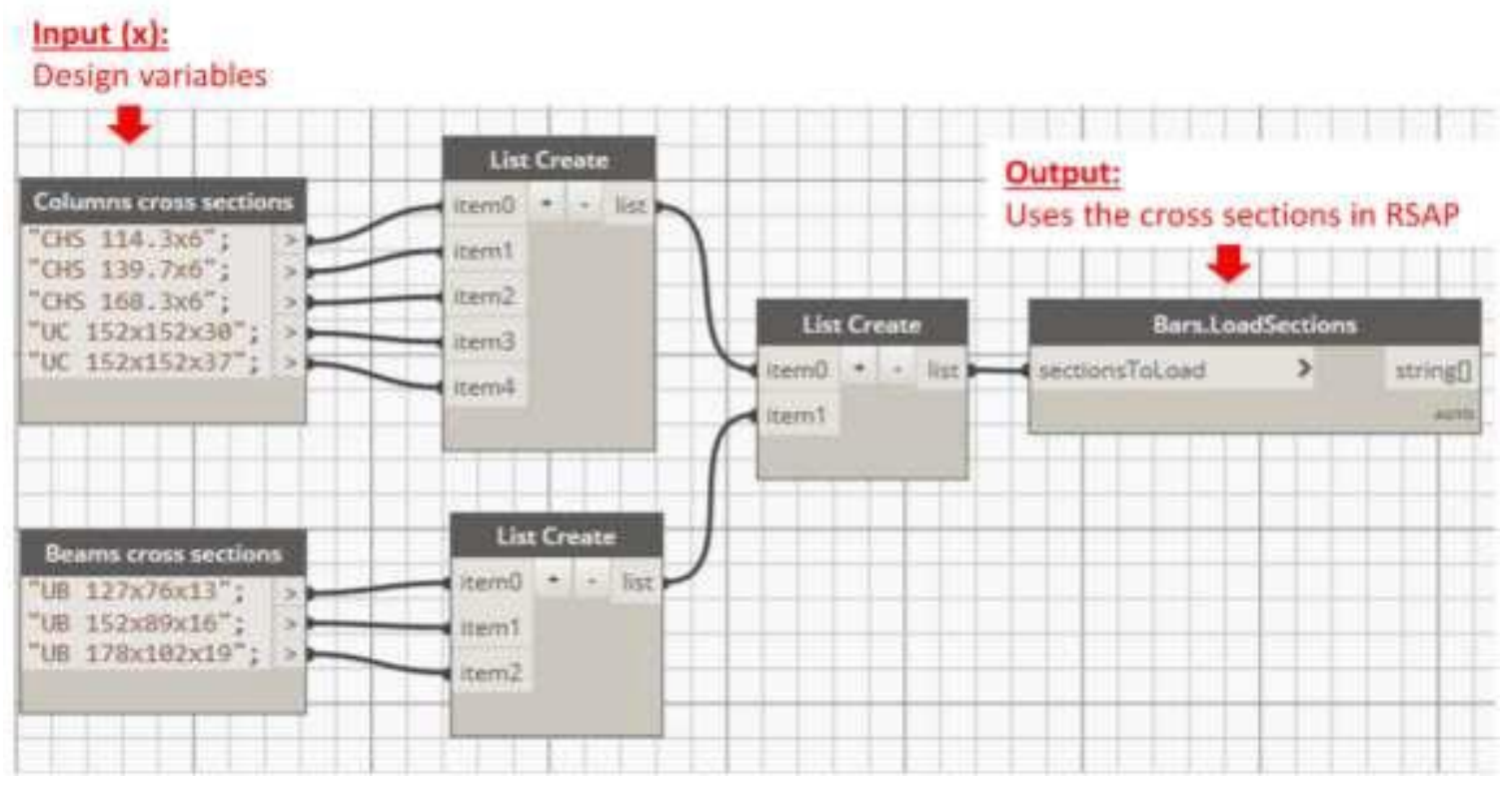

Figure 5: Load different cross sections for topology generator

\subsubsection{Output}

Finally, after the alternations of the building shape and topology arrangement, the system provides the designer with several alternative structural models - during early stages of structural design - and enables the designer to select the optimum design, among available options. This offers the design team with automatic synergy between architects and engineers in a BIM-based platform and provides them with alternative structural designs, with minimum human intervention needed. The combination of building shape optimisation and topology optimisation in BIM platform is the starting point of prototype that enables architects and engineers to cooperate effectively. According to Figure 6, this prototype includes four main parts: input, shape optimisation, topology and size optimisation and output. 


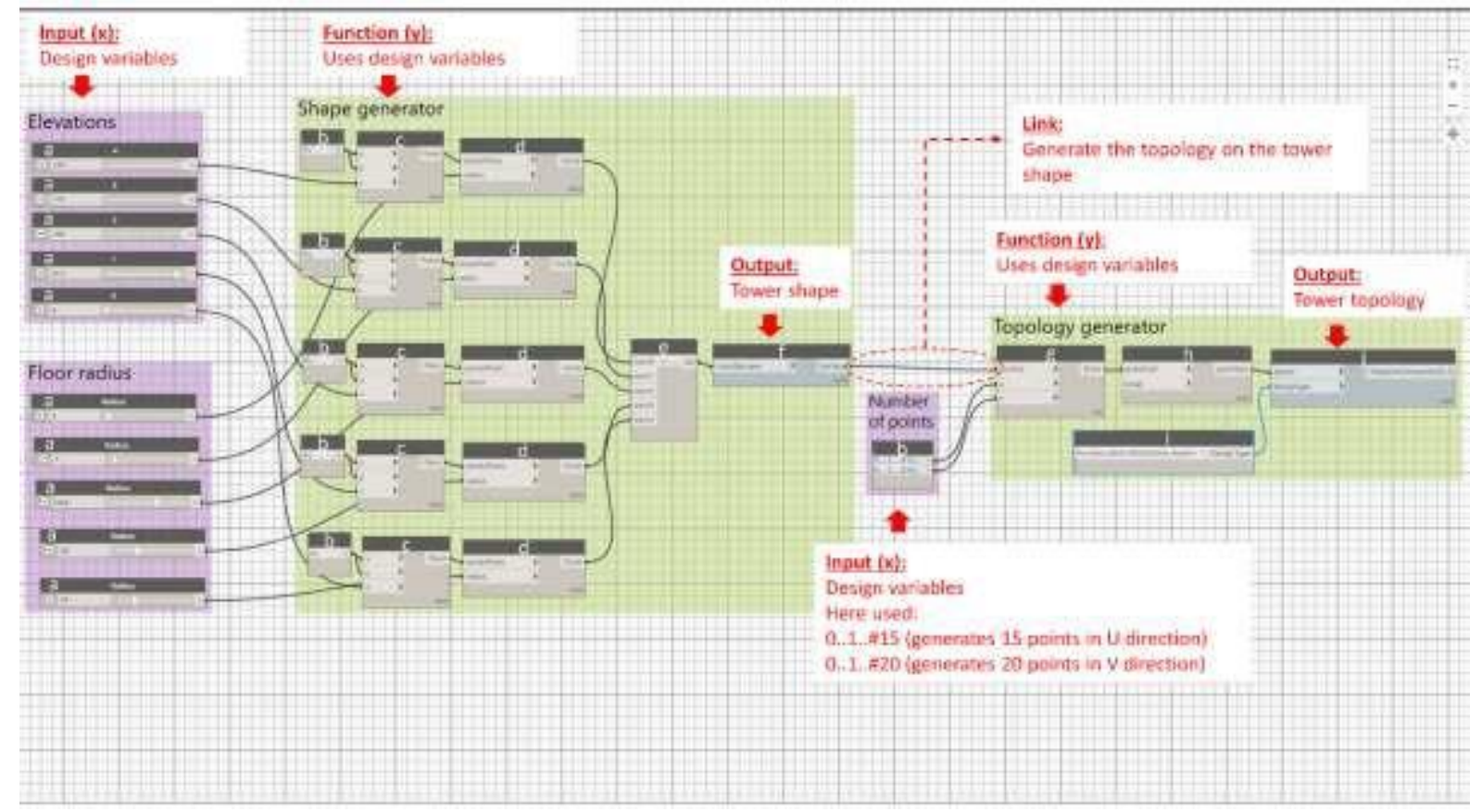

Figure 6: Tall building generator script (notes below)

a. Slider node: enable the designer to adjust the design by changing the design variables. In this script, the design is generated by 5 elevations and floor radiuses.

b. Code block node: this node is used to provide numbers where it is required.

c. Point.ByCoordinates node: this node uses three inputs as coordination in $x, y, z$ direction and generates a point. These points were used as the centre point of 5 different circular floors in in 5 different elevations.

d. Circle.ByCentrePointRadious node: this node uses a point and a number (radius) to generate circles, which will be used as floors.

e. List.Creat node: this node creates a list of inputs, in this case a list of circles.

f. Surface. ByLoft node: this node uses a list of curves (in this case a list of circles) and generates a surface (shape of the tower).

g. Surface.PointAtParameter node: this node uses a surface and two numbers ( $U$ and $V$ ) to generate points on a surface, in this case this node generates points on the surface of the tower. This point will be used as a place holder to use different patterns on the shape of the tower. changing the values of $U$ and $V$ changes the number of points and consequently changes the patterns on the shape of the tower.

h. PointGrid.ToQuadSet node: this node uses a set of four points to generate a pattern of quad on the shape of the tower. i. Family Type node: this node enables the designer to change the cross section of the elements to be used in the quad's patterns.

j. AdaptiveComponent.ByPoint node: this node uses a list of quad sets and a family type and to generate the entire topology of the 


\subsection{Preliminary production assessment}

As discussed, and illustrated in Figure 7, the structural design of Gherkin Tower relies on two primary structures in withstanding the loads: the diagrid and the core.

\section{Architectural criteria}

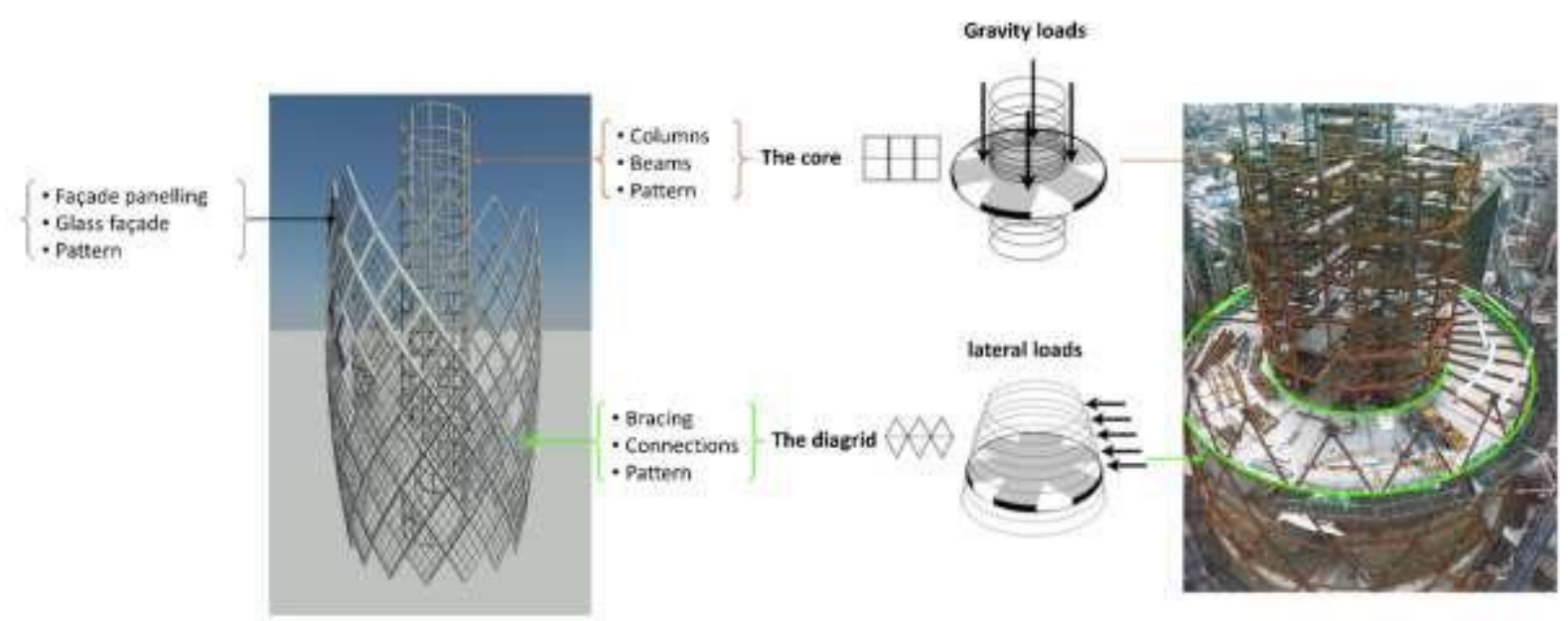

Figure 7: Integrated architectural-structural design

Figure 7 demonstrates that the core is located at the centre of the building to resist major gravity loads; it performs as a secondary structure for the diagrid. The diagrid creates structural shape of the Gherkin Tower. To design and optimise the core and diagrid separately, two different mathematical functions were defined in Dynamo, which used parametric variables like diameter of the floor along the height of the tower. Any change of these parametric variables is reflected on the structural model, automatically. Therefore, providing a series of input data (variables) will generate different alternatives for the structural design.

\subsubsection{Objective function}

Objective function is the main criterion in the design of any type of structure; optimisation, minimum weight, minimum cost and maximum stability can be used as objective functions. In structural optimisation, objective function should be formulated as a surrogate factor to explore other factors such as ductility, natural frequencies, P-D effects, buckling and stability to explore the most economic and 
feasible solution to the problem [21]. In the proposed PoC prototype, the use of precise formulation and functions for the automatic structural design and optimisation is crucial to obtain a proper solution. An accurate and comprehensive problem formulation should propose the design problem and maintain a high level of accuracy, during the evolutionary design process. In this case, the maximum stability is considered as an objective function to explore the most stable design of Gherkin Tower against the wind load. Therefore, a mathematical function is defined in Dynamo to use different sets of variables to design and analyse different options of the Gherkin Tower in RSA and compare the results in terms of stability against wind load and eventually propose the best option.

\subsubsection{Shape optimisation}

Building shape can affect architectural aesthetic integrity, structural safety and stability. Therefore, any decision on the shape of a building depends on reaching an agreement among architects and structural engineers. The proposed $\mathrm{PoC}$ prototype facilitates this by automating the structural design process based on the architectural model (boundary conditions). For instance, to improve safety and serviceability of tall buildings against strong winds, building shape optimisation in early architectural design stage is considered as the most efficient method to create a wind-resistant design [87]. Therefore, the proposed PoC prototype enables structural engineers and architects to work on a synchronised automatic platform and explore the optimum shape of the building; one that reduces the effect of wind load on the building. According to Figure 8, the cylindrical shape of Gherkin Tower allows the wind to move around the building and reduces the effect of the wind, while the cubic shape resists against the wind load. 

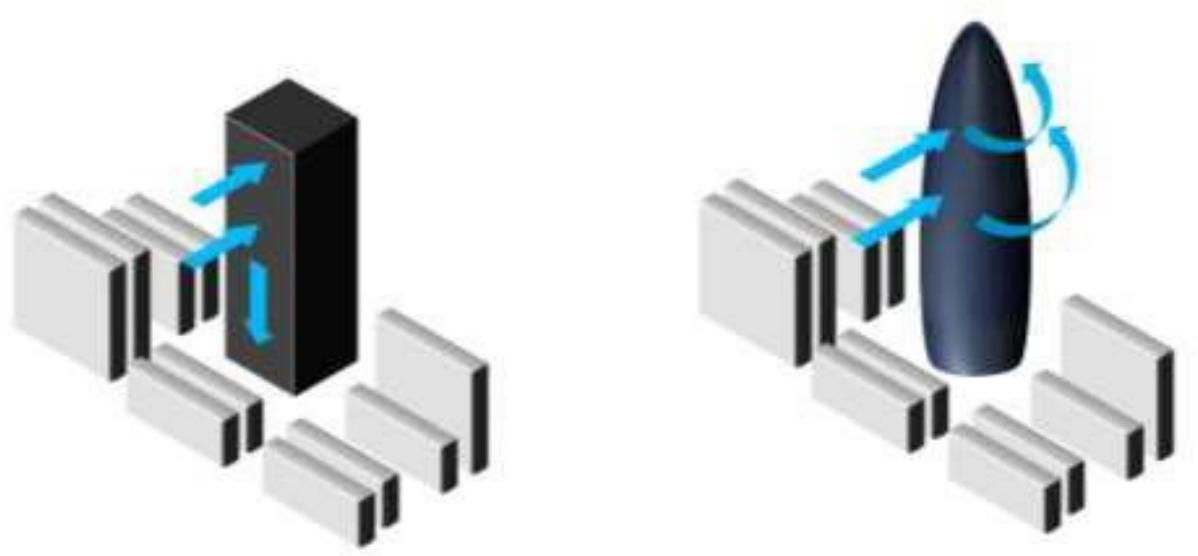

Figure 8: Effect of wind load on the shape of the building

In structural optimisation, some data are considered parameters (control variables) by means of which the structure varies until an optimum design with desired properties can be achieved. These parameters can vary based on designers' requirements [84].

Parameterisation of building shape design enables designers to define the building shape information as a set of variables and mathematical functions and provide a holistic method to generate complex and irregular building shapes.

The prototype suggested here modifies the building shape parameterisation in two directions horizontal and vertical. The horizontal direction represents the shape of the floor plan and the area of the building; the vertical direction defines the height of the building. There are various types of base floor plans designed by parametric representation of geometry. Like the horizontal direction, there are various types of building shape in vertical direction. The geometry of the floor plan shape above the base floor can be transformed using different transformation functions including no change translation, scaling and rotation. 



Figure 9: Horizontal and vertical transformation

Figure 9 demonstrates two types of horizontal and vertical transformations. The left side tower uses floor plan shapes with a series of squares, where the arrangements of squares changes along the height of the tower. On the other hand, the right-side tower uses a circle floor base plan shape, where the radius of the circle changes along the height of the tower. The solution proposed here uses this method as a mathematical function in Dynamo to define the shape of Gherkin Tower by using two variables. That is, the diameter of circles and the level of the centre point of each circle are considered as variables that create the shape of the tower (Please see Figure 10). Hence, providing various series of circle radius and circle centre point levels generate different shapes for the tower. Figure 10 demonstrates 4 different options of tower shapes generated by varying the value of parametric variables. All the design options have the same site boundary constraints; they all have the same height of $179 \mathrm{~m}$, the same base floor external diameter of $50 \mathrm{~m}$ and the maximum floor external diameter of $56.15 \mathrm{~m}$. 


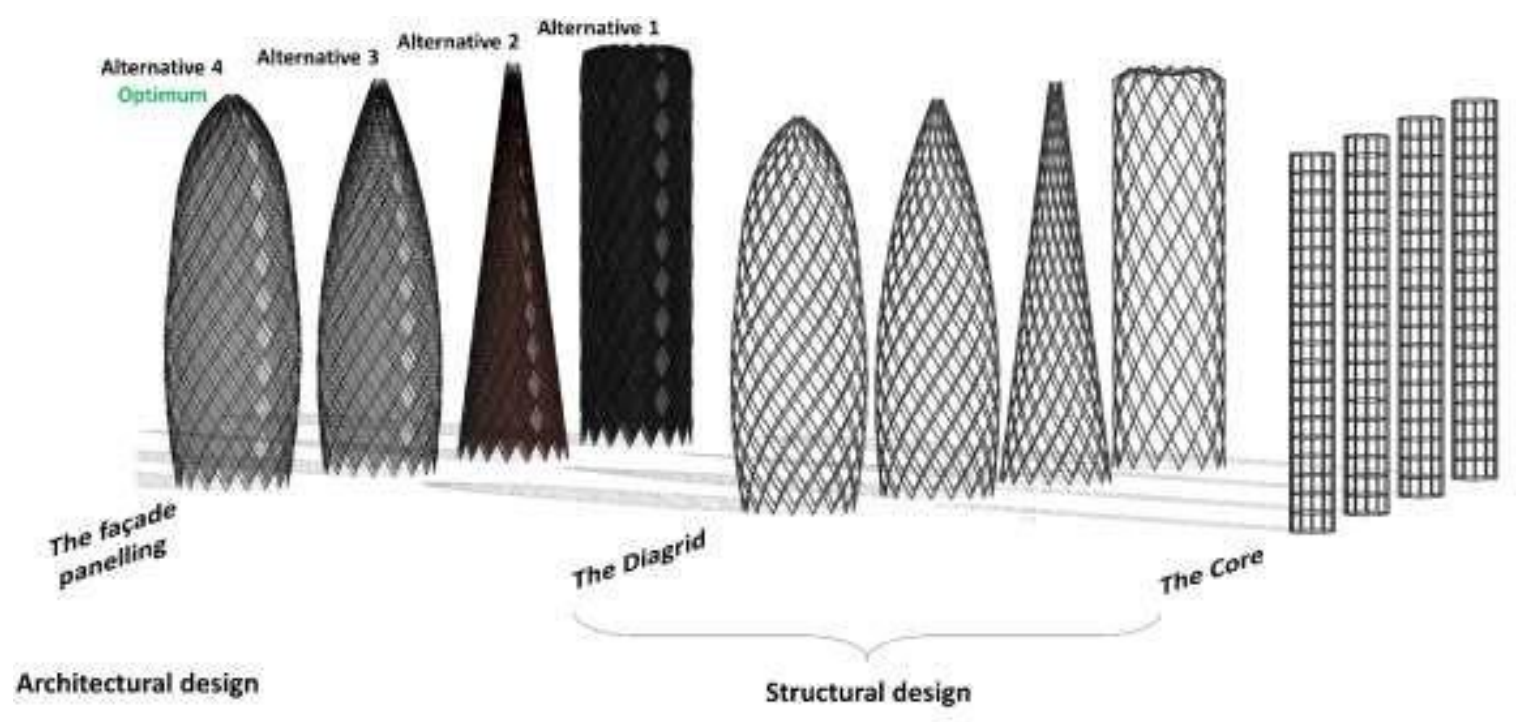

Figure 10: Shape optimisation of the Gherkin tower

\subsubsection{Topology optimisation}

The optimum option of the tower shape with architectural and structural efficiency is adopted and the design proceeds to the structural topology design and optimisation. Topology optimisation is known as one of the most effective methods at the conceptual design stage of most engineering applications [88]. This method is a mathematical and often gradient-based design approach to explore the optimum location in a design domain to locate the material according to the applied load and boundary conditions [21].

This prototype defined three different mathematical functions to design the core structure, the diagrid structure and the façade panelling. Each approach has a formulation to solve the design problem; it uses specific parametric constraints (variables) to design different topology options. In this case, the diagrid structure and the architectural façade were designed by using quad.diamond panel node from LunchBox Quad by face package [89] in Dynamo to create diamond features. In addition, the core structure was designed by using surface panelling package to create rectangular features.

By varying the variables of each function, the corresponding topology varies. Therefore, different topology design options will be designed and analysed in RSA and the results will be used for 
optimisation, to choose the best model between different options. Even though design alternatives with more diagrid patterns might be preferable from the structural engineers' point of view, these design alternatives may not be practically and aesthetically desirable for contractors, architects and clients. The density spaced diamond diagrids may reduce the aesthetic value of the building and creates less attractive architectural design. Moreover, use of more diagrid diamond patterns may also affect energy consumption, as it creates blockage for the sunlight penetrating the building and reduces the natural light of the building. This kind of conflict requires constant collaboration and communication between architects and engineers during the design process.

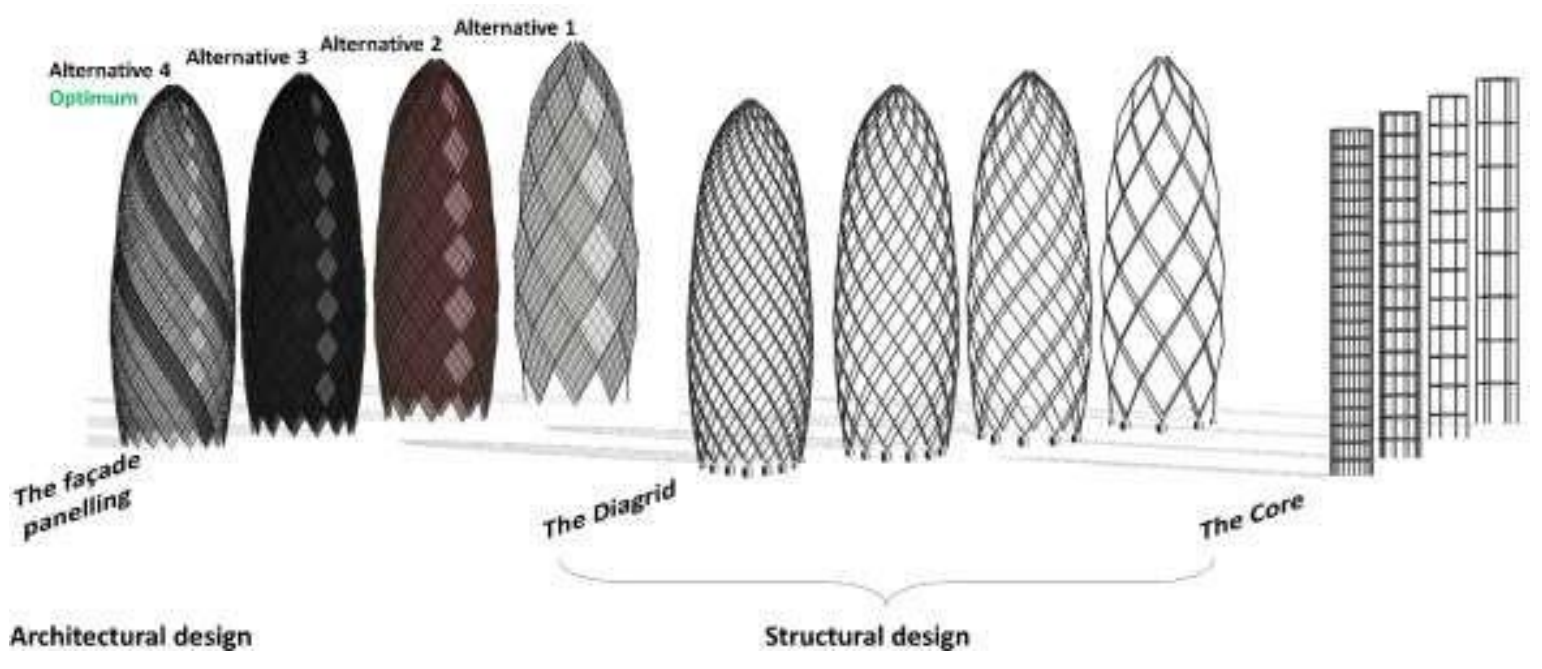

Figure 11: Topology optimisation of the Gherkin Tower

Figure 11 demonstrates four different variations of structural topology designs, which are linked to the architectural façade panelling design. In Figure 11, the architectural façade panelling design and the structural topology design (the diagrid and the core) are separated, to visualise the concept of automatic integrated design between architectural and structural models during topology optimisation process.

\subsubsection{Size optimisation}

After accurate shape and topology optimisation, structural member size optimisation is an essential step to conduct a precise structural design performance evaluation. Size optimisation or cross-section optimisation is often used to explore the optimum cross-section area of column elements and beam 
elements in a frame, to find the optimum thicknesses of plate elements, while satisfying the design requirements [21]. According to Figure 12, the diagrid and the core elements consist of parametric cross-sections that can be adjusted to explore the optimum solution. Like the shape and topology optimisation, this prototype defines a mathematical function to use a series of parametric variables and generate different structural models with various cross section sizes (see Figure 12).

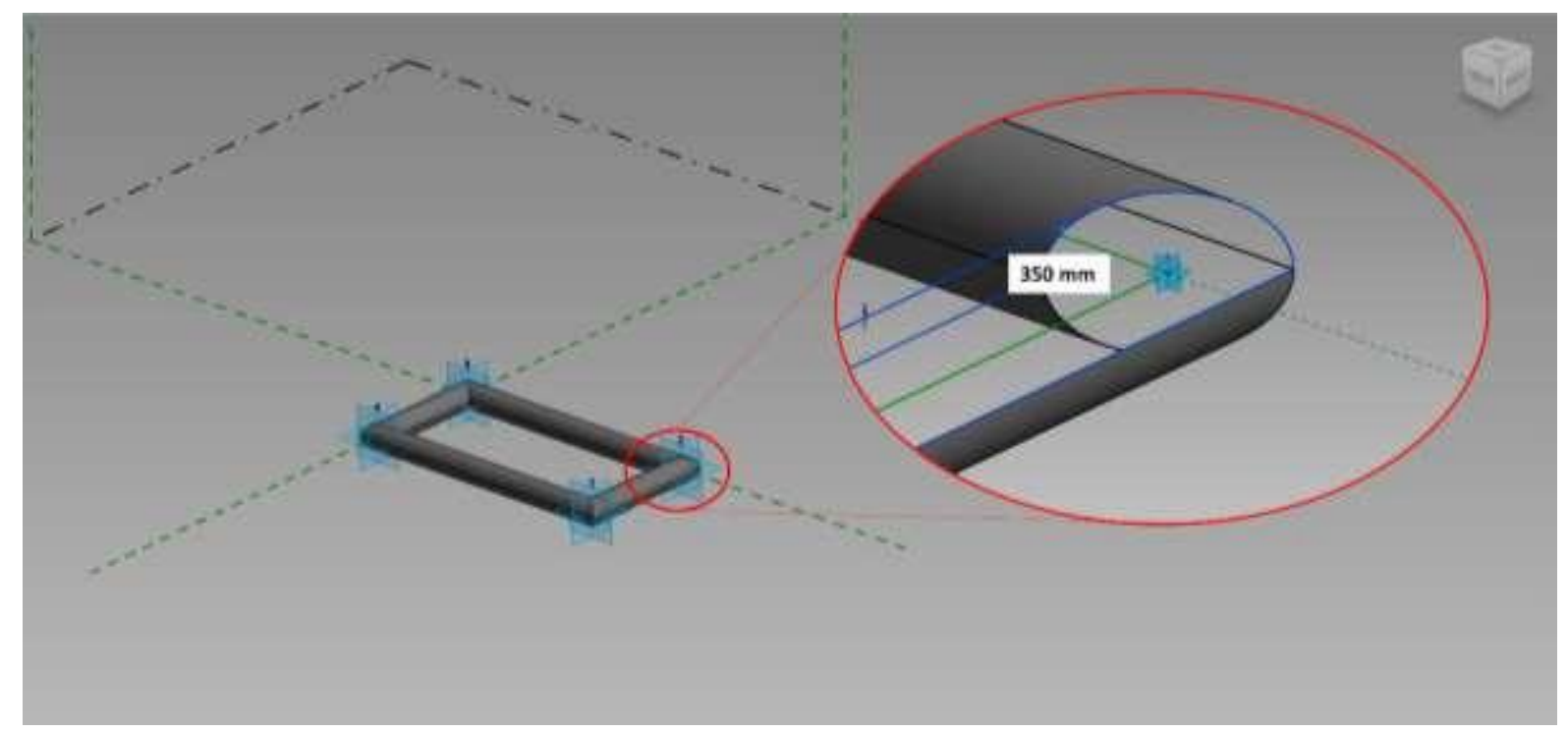

Figure 12: Parametric data of Revit family is used for size optimisation of the Gherkin Tower

\section{Discussion of findings}

Despite the advancements provided through BIM, federated models and CDE, the design procedure of buildings remains a loosely-couple system. The outcome of the project reported in this paper provides a much-needed toolset and associated procedures to assist in integrating various actors across the design procedure of buildings. The PoC offers a workable solution to enhance efficiency and reduce conflicts and clashes that occur as a result of fragmented and silo-based procedure of structural design. The study stands out among similar ones, given that it provides the first of its kind toolset that relies on an automated synergy and computation analysis procedure to use architectural parametric data for multifaceted optimising of structural design. This extends the capabilities of federated BIM models. With using the solution, there will be no need for the exchange of files among various disciplines, given that 
the computational procedures and structural design analyses can take place inside federated models and $\mathrm{CDE}$, as one step further towards BIM level 3.

With the above in mind, the study contributes to the field through extending the outcomes of previous studies that managed to provide optimisation for structural design, albeit in one dimension like shape, topology $[53,90]$ and size $[91,92]$ in structural design, while the prototype here considers all these dimensions simultaneously.

The study also provides a practical demonstration for researchers who recommended merging architects and structural engineers in one system, making their practices inseparable, to shift from current practices to a fully integrated architectural/structural design system [93-98]. The study also broadens the boundary of application for previous attempts that focused on structural optimisation of particular structures like truss members [92,99-105]. The proposed framework here, based on tall buildings captures maximum complexity and therefore can be rolled over to various type of structures including buildings, as well as, infrastructure projects like bridges, trusses high-rise towers, etc.

\section{Practical implications}

Apart from theoretical contributions, as discussed, the solution provided here would be appealing to the world of practice, particularly for practitioners active in various fields of structural design and different type of structures. The solution will be invaluable, as discussed below.

- This solution enables designers to develop mathematical functions and direct machines to extract what they need from architectural models, to be used for structural design, based on defined parameters that vary and generate alternative structural design solutions. This gives practitioners great flexibility to customise the system for certain projects, clients with various expectations and different demands. As an example, the solution can easily be adjusted for different design codes for steel/ aluminium, timber and concrete structures in different regions 
(see Figure 13).


Figure 13: Different design codes in various regions.

- This method provides great efficiency and provides a wide range of alternatives for structural design. Limitation of time and labour and human error prevent designers from exploring all available solutions; the proposed system overcomes these and provides designers with higher efficiency to explore all possibilities within the boundaries of their resources.

- The prototype relies on common tools and software available to most design practitioners. As such, the solution is cost effectives and feasible even for small businesses.

\section{Conclusion}

Despite the permeation of BIM into the construction market, applications of BIM in structural design are still limited, as a gap acknowledged in the literature. This study provides a background to address this gap and showcases the potential and capability of BIM to facilitate structural design. Through the collaboration lens, the study provides a solution to enhance collaboration among team members involved in BIM-enabled projects, looking into the potential of the proposed solution from a broader 
picture. In broad terms, this paper adds value to the body of knowledge by showcasing the possibilities of shifting from discipline-based design and exchange of files towards adopting BIM Level 3. The paper presents a readily available and cost effectiveness solution, a fully automated integrated design with intelligent computing-enabled federated BIM models. These all, encapsulated in the proposed solution, resemble the fundamental aspects needed for moving towards BIM level 3.

Acknowledging the limitations, the solution provided here is a starting point and a basic attempt in technical terms. That said, the study serves the purpose of furthering knowledge on possible solutions to move towards BIM Level 3. It would provoke broader discussions and raising awareness on the existing possibilities for enhancing collaboration among disciplines and breaking the silos based on available tools and technology. Arguments presented here provide a fertile area for research, to focus on improving the idea proposed here through creating user-friendly platforms that automate the procedure based on a set of variables as inputs to creates efficient design alternatives for stakeholders with no design knowledge like clients, owners, end users, etc. As another area for further exploration, the experience shared here brings to light the requirements of future design professional in terms of their knowledge, skills and abilities (KSAs). Future research must explore the necessity of a new generation of designers with programming and coding capabilities for construction-related curricula at universities. So too, researchers must target further investigation and development in the RSA API are to expand the workability of the prototype for automatic synergy between architectural and structural design, analysis, optimisation and evaluation.

\section{Reference}

[1] Palomar IJ, Valldecabres JLG, Tzortzopoulos P, Pellicer E. An online platform to unify and synchronise heritage architecture information. Autom Constr 2020;110:103008. doi:https://doi.org/10.1016/j.autcon.2019.103008.

[2] Ku K, Pollalis SN, Fischer MA, Shelden DR. 3D model-based collaboration in design development and construction of complex shaped buildings. Electron J Inf Technol Constr 2008;13:458-85.

[3] Leite F. BIM for Design Coordination: A Virtual Design and Construction Guide for Designers, General Contractors, and MEP Subcontractors. 2019. 
[4] Liu Y, Nederveen S Van, Project MH-IJ of, 2017 U. Understanding effects of BIM on collaborative design and construction: An empirical study in China. Elsevier 2017.

[5] Abrishami S, Grenfell-Baines (, Goulding J, Pour F, Grenfell-Baines R(, Ganah A. Virtual Generative BIM Workspace for Maximising AEC Conceptual Design Innovation: A Paradigm of Future Opportunities 2015. doi:10.1108/Cl-07-2014-0036.

[6] Hamidavi T, Abrishami S, Ponterosso P, Begg D. Optimisation of Structural Design by Integrating Genetic Algorithms in the Building Information Modelling Environment. Int J Civ Environ Eng 2018;12. doi:1307-6892/10009523.

[7] Macdonald AJ, Macdonald AJ. Structure and architecture. Struct. Archit., 2019. doi:10.4324/9781315210513-11.

[8] Hurol Y. Ethical Considerations for a Better Collaboration Between Architects and Structural Engineers: Design of Buildings with Reinforced Concrete Frame Systems in Earthquake Zones. Sci Eng Ethics 2014;20:597-612. doi:10.1007/s11948-013-9453-4.

[9] Larsen OP, Tyas A. Conceptual Structural Design: Bridging the Gap between Architects and Engineers. Thomas Telford Ltd; 2003. doi:10.1680/csdbtgbaae.32354.

[10] Ciribini ALC, Mastrolembo Ventura S, Paneroni M. Implementation of an interoperable process to optimise design and construction phases of a residential building: A BIM Pilot Project. Autom Constr 2016;71:62-73. doi:10.1016/j.autcon.2016.03.005.

[11] Hamidavi T, ... SA-... J of C, 2018 U. Optimisation of structural design by integrating genetic algorithms in the building information modelling environment. Int J Civ Environ Eng n.d.

[12] Sheikhkhoshkar M, Pour Rahimian F, Kaveh MH, Hosseini MR, Edwards DJ. Automated planning of concrete joint layouts with 4D-BIM. Autom Constr 2019;107.

doi:10.1016/j.autcon.2019.102943.

[13] Banihashemi S, Tabadkani A, Hosseini MR. Integration of parametric design into modular coordination: A construction waste reduction workflow. Autom Constr 2018;88:1-12. doi:10.1016/j.autcon.2017.12.026.

[14] Hosseini MR, Maghrebi M, Akbarnezhad A, Martek I, Arashpour M. Analysis of Citation Networks in Building Information Modeling Research. J Constr Eng Manag 2018;144. doi:10.1061/(ASCE)CO.1943-7862.0001492.

[15] Vilutiene T, Kalibatiene D, Hosseini MR, Pellicer E, Zavadskas EK. Building information modeling (BIM) for structural engineering: A bibliometric analysis of the literature. Adv Civ Eng 2019;2019. doi:10.1155/2019/5290690.

[16] Pärn EA, Edwards DJ, Sing MCP. Origins and probabilities of MEP and structural design clashes within a federated BIM model. Autom Constr 2018;85:209-19. doi:10.1016/j.autcon.2017.09.010.

[17] Mignone G, Hosseini MR, Chileshe N, Arashpour M. Enhancing collaboration in BIM-based construction networks through organisational discontinuity theory: a case study of the new Royal Adelaide Hospital. Archit Eng Des Manag 2016;12:333-52. doi:10.1080/17452007.2016.1169987.

[18] Oraee M, Hosseini MR, Edwards DJ, Li H, Papadonikolaki E, Cao D. Collaboration barriers in BIMbased construction networks: A conceptual model. Int J Proj Manag 2019;37:839-54. doi:10.1016/j.ijproman.2019.05.004.

[19] Darko A, Chan APC, Adabre MA, Edwards DJ, Hosseini MR, Ameyaw EE. Artificial intelligence in the AEC industry: Scientometric analysis and visualization of research activities. Autom Constr 
2020;112:103081. doi:https://doi.org/10.1016/j.autcon.2020.103081.

[20] Papadonikolaki E. Loosely Coupled Systems of Innovation: Aligning BIM Adoption with Implementation in Dutch Construction. J Manag Eng 2018;34. doi:10.1061/(ASCE)ME.19435479.0000644 .

[21] Beghini LL, Beghini A, Katz N, Baker WF, Paulino GH. Connecting architecture and engineering through structural topology optimization. Eng Struct 2014. doi:10.1016/j.engstruct.2013.10.032.

[22] Durdyev S, Hosseini MR, Martek I, Ismail S, Arashpour M. Barriers to the use of integrated project delivery (IPD): a quantified model for Malaysia. Eng Constr Archit Manag 2019. doi:10.1108/ECAM-12-2018-0535.

[23] Pärn EA, Edwards DJ, Sing MCP. The building information modelling trajectory in facilities management: A review. Autom Constr 2017;75:45-55. doi:10.1016/j.autcon.2016.12.003.

[24] Kraatz JA, Sanchez AX, Hampson KD. Digital Modeling, Integrated Project Delivery and Industry Transformation: An Australian Case Study. Buildings 2014;4:453-66. doi:10.3390/buildings4030453.

[25] Merschbrock C, Fellow R. UNORCHESTRATED SYMPHONY: THE CASE OF INTER-ORGANIZATIONAL COLLABORATION IN DIGITAL CONSTRUCTION DESIGN. vol. 17. 2012.

[26] Emmitt S, Ruikar K. Collaborative design management. vol. 9780203819. 2013. doi:10.4324/9780203819128.

[27] Kuiper I, Holzer D. Rethinking the contractual context for Building Information Modelling (BIM) in the Australian built environment industry. Australas J Constr Econ Build 2013;13:1-17. doi:10.5130/ajceb.v13i4.3630.

[28] Oraee M, Hosseini MR, Papadonikolaki E, Palliyaguru R, Arashpour M. Collaboration in BIM-based construction networks: A bibliometric-qualitative literature review. Int J Proj Manag 2017;35:1288-301. doi:10.1016/j.ijproman.2017.07.001.

[29] Olatunji OA. A preliminary review on the legal implications of BIM and model ownership. Electron J Inf Technol Constr 2011;16:687-96.

[30] Pishdad-Bozorgi P. Case Studies on the Role of Integrated Project Delivery (IPD) Approach on the Establishment and Promotion of Trust. Int J Constr Educ Res 2017;13:102-24. doi:10.1080/15578771.2016.1226213.

[31] Teng Y, Li X, Wu P, Wang X. Using cooperative game theory to determine profit distribution in IPD projects. Int J Constr Manag 2019;19:32-45. doi:10.1080/15623599.2017.1358075.

[32] Hamzeh F, Rached F, Hraoui Y, Karam AJ, Malaeb Z, El Asmar M, et al. Integrated project delivery as an enabler for collaboration: a Middle East perspective. Built Environ Proj Asset Manag 2019;9:334-47. doi:10.1108/BEPAM-05-2018-0084.

[33] Merschbrock C, Munkvold EB. How is building information modeling influenced by project complexity?: A cross-case analysis of e-collaboration performance in building construction. IgiGlobalCom 2014.

[34] Zhang X-Y, Hu Z-Z, Wang H-W, Kassem M. An Industry Foundation Classes (IFC) web-based approach and Platform for Bi-Drectional conversion of structural analysis models. Comput. Civ. Build. Eng., 2014, p. 390-7.

[35] Chan CM. Optimal lateral stiffness design of tall buildings of mixed steel and concrete construction. Struct Des Tall Build 2001. doi:10.1002/tal.170. 
[36] Xie J. Aerodynamic optimization of super-tall buildings and its effectiveness assessment. J Wind Eng Ind Aerodyn 2014;130:88-98. doi:10.1016/j.jweia.2014.04.004.

[37] Foraboschi P, Mercanzin M, Trabucco D. Sustainable structural design of tall buildings based on embodied energy. Energy Build 2014;68:254-69. doi:10.1016/j.enbuild.2013.09.003.

[38] Garber R. Optimisation stories: The impact of building information modelling on contemporary design practice. Archit Des 2009;79:6-13. doi:10.1002/ad.842.

[39] Baldock R, Shea K. Structural Topology Optimization of Braced Steel Frameworks Using Genetic Programming. In: Smith IFC, editor. Intell. Comput. Eng. Archit., Berlin, Heidelberg: Springer Berlin Heidelberg; 2006, p. 54-61.

[40] Hofmeyer H, Davila Delgado JM. Automated design studies: Topology versus One-Step Evolutionary Structural Optimisation. Adv Eng Informatics 2013;27:427-43. doi:10.1016/J.AEI.2013.03.003.

[41] Mueller CT, Ochsendorf JA. Combining structural performance and designer preferences in evolutionary design space exploration. Autom Constr 2015. doi:10.1016/j.autcon.2015.02.011.

[42] Vermeulen D. Dynam(o)ite your Design for Engineers - part 1. Revit beyond BIM 2015.

[43] Richardson JN, Nordenson G, Laberenne R, Coelho RF, Adriaenssens S. Flexible optimum design of a bracing system for façade design using multiobjective Genetic Algorithms. Autom Constr 2013;32:80-7. doi:10.1016/j.autcon.2012.12.018.

[44] Dutta S, Cai Y, Huang L, Zheng J. Automatic re-planning of lifting paths for robotized tower cranes in dynamic BIM environments. Autom Constr 2020;110. doi:10.1016/j.autcon.2019.102998.

[45] Zayed T, Mohamed E. A case productivity model for automatic climbing system. Eng Constr Archit Manag 2014;21:33-50. doi:10.1108/ECAM-02-2012-0015.

[46] Li QS, Zou XK, Wu JR, Wang Q. Integrated wind-induced response analysis and design optimization of tall steel buildings using Micro-GA. Struct Des Tall Spec Build 2011;20:951-71. doi:10.1002/tal.569.

[47] Chunyu D, Li W. High building layout design based on emotional differential evolution algorithm. Cluster Comput 2019;22:5001-7. doi:10.1007/s10586-018-2452-0.

[48] Wang S, Mahin SA. High-performance computer-aided optimization of viscous dampers for improving the seismic performance of a tall building. Soil Dyn Earthq Eng 2018;113:454-61. doi:10.1016/j.soildyn.2018.06.008.

[49] Shahin HSM. Adaptive building envelopes of multistory buildings as an example of high performance building skins. Alexandria Eng J 2019;58:345-52. doi:10.1016/j.aej.2018.11.013.

[50] Holzer D, Burry MC, Hough R. Linking parametric design and structural analysis to foster transdisciplinary design collaboration. CAADRIA 2007 - Assoc. Comput. Archit. Des. Res. Asia Digit. Glob., 2007.

[51] Holzer D, Tang J, Xie M, Burry M. Design Using Evolutionary Optimisation and Associative Geometry Architect Engineer interaction 2002.

[52] Stromberg LL, Beghini A, Baker WF, Paulino GH. Topology optimization for braced frames: Combining continuum and beam/column elements. Eng Struct 2012. doi:10.1016/j.engstruct.2011.12.034.

[53] Tsavdaridis KD, Kingman JJ, Toropov V V. Application of structural topology optimisation to 
perforated steel beams. Comput Struct 2015. doi:10.1016/j.compstruc.2015.05.004.

[54] Kazakis G, Kanellopoulos I, Sotiropoulos S, Lagaros ND. Topology optimization aided structural design: Interpretation, computational aspects and 3D printing. Heliyon 2017. doi:10.1016/j.heliyon.2017.e00431.

[55] Rahmani Asl M, Zarrinmehr S, Bergin M, Yan W. BPOpt: A framework for BIM-based performance optimization. Energy Build 2015. doi:10.1016/j.enbuild.2015.09.011.

[56] AsI MR, Stoupine A, Zarrinmehr S, Yan W. Optimo: A BIM-based multi-objective optimization tool utilizing visual programming for high performance building design 2015.

[57] Rahmani AsI M, Bergin M, Menter A, Yan W. BIM-based Parametric Building Energy Performance Multi-Objective Optimization. 32nd eCAADe Conf. 224 10, 2014.

[58] Schlueter A, Geyer P. Linking BIM and Design of Experiments to balance architectural and technical design factors for energy performance. Autom Constr 2018;86:33-43. doi:10.1016/j.autcon.2017.10.021.

[59] Mora R, Bédard C, Rivard H. A geometric modelling framework for conceptual structural design from early digital architectural models. Adv Eng Informatics 2008. doi:10.1016/j.aei.2007.03.003.

[60] Park SM, Elnimeiri M, Sharpe D, Krawczyk R. Tall building form generation by parametric design process. CTBUH 2004 Seoul Conf 2004.

[61] Elnimeiri M, Almusharaf A. A Performance-Based Design Approach for Early Tall Building Form Development. CAAD - Cities - Sustain 5th Int Conf Proc Arab Soc Comput Aided Archit Des 2010:39-49.

[62] Chan C-M, Grierson DE, Sherbourne AN. Automatic Optimal Design of Tall Steel Building Frameworks. J Struct Eng 2002. doi:10.1061/(asce)0733-9445(1995)121:5(838).

[63] Bezabeh MA, Bitsuamlak GT, Popovski M, Tesfamariam S. Probabilistic serviceabilityperformance assessment of tall mass-timber buildings subjected to stochastic wind loads: Part I structural design and wind tunnel testing. J Wind Eng Ind Aerodyn 2018;181:85-103. doi:10.1016/j.jweia.2018.08.012.

[64] Sharma A, Mittal H, Gairola A. Mitigation of wind load on tall buildings through aerodynamic modifications: Review. J Build Eng 2018;18:180-94. doi:10.1016/j.jobe.2018.03.005.

[65] Zhao L, Cui W, Zhan Y, Wang Z, Liang Y, Ge Y. Optimal structural design searching algorithm for cooling towers based on typical adverse wind load patterns. Thin-Walled Struct 2020;151:106740. doi:10.1016/j.tws.2020.106740.

[66] Love JS, Taylor ZJ, Yakymyk WN. Determining the peak spatial and resultant accelerations of tall buildings tested in the wind tunnel. J Wind Eng Ind Aerodyn 2020;202:104225. doi:10.1016/j.jweia.2020.104225.

[67] Yan B, Li QS. Wind tunnel study of interference effects between twin super-tall buildings with aerodynamic modifications. J Wind Eng Ind Aerodyn 2016;156:129-45. doi:10.1016/j.jweia.2016.08.001.

[68] Zheng C, Xie Y, Khan M, Wu Y, Liu J. Wind-induced responses of tall buildings under combined aerodynamic control. Eng Struct 2018;175:86-100. doi:10.1016/j.engstruct.2018.08.031.

[69] Design Book. The Gherkin - Famous Buildings and Architecture of London 2020. http://www.designbookmag.com/thegerkin.htm (accessed January 15, 2020). 
[70] ARUP. 3D Modelling for The Gherkin - Arup 2020. https://www.arup.com/projects/30-st-maryaxe (accessed January 15, 2020).

[71] Foster and Partners. 30 St Mary Axe | Offices and Headquarters | Foster + Partners 2004. https://www.fosterandpartners.com/projects/30-st-mary-axe/ (accessed January 15, 2020).

[72] Al-Kodmany K. The vertical city : a sustainable development model. 2018.

[73] Spray S, Ruffle M. Skyscrapers. 2018.

[74] Singh V, Gu N. Towards an integrated generative design framework. Des Stud 2012. doi:10.1016/j.destud.2011.06.001.

[75] Agkathidis A. Generative Design : Form-Finding Techniques in Architecture. Laurence. King Publishing; 2015.

[76] Issa RRA, Olbina S. Building information modeling: Applications and practices. 2015. doi:10.1061/9780784413982.

[77] Rahmani AsI M, Bergin M, Menter A, Yan W. BIM-based parametric building energy performance multi-objective optimization 2014.

[78] Grasshopper. Grasshopper - algorithmic modeling for Rhino n.d https://www.grasshopper3d.com/ (accessed January 10, 2020).

[79] Mirjalili SZ, Mirjalili S, Saremi S, Faris H, Aljarah I. Grasshopper optimization algorithm for multiobjective optimization problems. Appl Intell 2018;48:805-20. doi:10.1007/s10489-017-1019-8.

[80] Dynamo BIM. Dynamo BIM 2019. https://dynamobim.org/.

[81] Kilkelly M. What Is Dynamo and 5 Reasons You Should be Using It - ArchSmarter - 2018. https://archsmarter.com/what-is-dynamo-revit/ (accessed January 10, 2020).

[82] Christensen P, Klarbring A. An Introduction to Structural Optimization. Springer Netherlands; 2009. doi:10.1007/978-1-4020-8666-3.

[83] Bendsøe MP, Sigmund O (Ole). Topology optimization : theory, methods, and applications. Springer; 2003.

[84] J. H, E. MRA. Introduction to Shape Optimization - Theory, Approximation, and Computation. Society for Industrial and Applied Mathematics, 2015.; 2015.

[85] Sigmund O. Topology optimization: A tool for the tailoring of structures and materials. Philos Trans R Soc A Math Phys Eng Sci 2000. doi:10.1098/rsta.2000.0528.

[86] Krog L, Tucker A, Kemp M, Boyd R. Topology Optimisation of Aircraft Wing Box Ribs, 2012. doi:10.2514/6.2004-4481.

[87] Tang J, Xie YM, Felicetti P. Conceptual design of buildings subjected to wind load by using topology optimization. Wind Struct An Int J 2014;18:21-35. doi:10.12989/was.2014.18.1.021.

[88] Zhu J-H, Zhang W-H, Xia L. Topology Optimization in Aircraft and Aerospace Structures Design. Arch Comput Methods Eng 2016;23:595-622. doi:10.1007/s11831-015-9151-2.

[89] Johnson lukes. Lunchbox - Dynamo Nodes 2016. https://dynamonodes.com/category/lunchbox/ (accessed January 10, 2020).

[90] Wu C-Y, Tseng K-Y. Topology optimization of structures using modified binary differential evolution. Struct Multidiscip Optim 2010;42:939-53. doi:10.1007/s00158-010-0523-9. 
[91] Jalili S, Hosseinzadeh Y. Design optimization of truss structures with continuous anddiscrete variables by hybrid of biogeography-basedoptimization and differential evolution methods. Struct Des Tall Spec Build 2018;27:e1495. doi:10.1002/tal.1495.

[92] Hasançebi O, Çarbaş S, Doğan E, Erdal F, Saka MP. Performance evaluation of metaheuristic search techniques in the optimum design of real size pin jointed structures. Comput Struct 2009;87:284-302. doi:https://doi.org/10.1016/j.compstruc.2009.01.002.

[93] Khan Y. Engineering architecture: the vision of Fazlur R. Khan 2004.

[94] Addis W. Building: 3000 years of design engineering and construction. 2007.

[95] Schueller W. Building Support Structures: Analysis and Design Using SAP2000 Software 2008.

[96] Billington D, Doig J, Guthrie J. The art of structural design: A Swiss legacy 2003.

[97] Sandaker B. On span and space: exploring structures in architecture. 2007.

[98] Nawari NO. Automating codes conformance in structural domain. Congr. Comput. Civ. Eng. Proc., 2011, p. 569-77. doi:10.1061/41182(416)70.

[99] Kaveh A, Ghazaan MI. A comparative study of CBO and ECBO for optimal design of skeletal structures. Comput Struct 2015;153:137-47. doi:https://doi.org/10.1016/j.compstruc.2015.02.028.

[100] Kaveh A, Mahdavi VR. Colliding Bodies Optimization method for optimum discrete design of truss structures. Comput Struct 2014;139:43-53.

doi:https://doi.org/10.1016/j.compstruc.2014.04.006.

[101] Miguel LFF, Miguel LFF. Shape and size optimization of truss structures considering dynamic constraints through modern metaheuristic algorithms. Expert Syst Appl 2012;39:9458-67. doi:https://doi.org/10.1016/j.eswa.2012.02.113.

[102] Dede T, Bekiroğlu S, Ayvaz Y. Weight minimization of trusses with genetic algorithm. Appl Soft Comput 2011;11:2565-75. doi:https://doi.org/10.1016/j.asoc.2010.10.006.

[103] Gholizadeh S. Layout optimization of truss structures by hybridizing cellular automata and particle swarm optimization. Comput Struct 2013;125:86-99. doi:https://doi.org/10.1016/j.compstruc.2013.04.024.

[104] Miguel LFF, Lopez RH, Miguel LFF. Multimodal size, shape, and topology optimisation of truss structures using the Firefly algorithm. Adv Eng Softw 2013;56:23-37. doi:https://doi.org/10.1016/j.advengsoft.2012.11.006.

[105] Degertekin SO. Improved harmony search algorithms for sizing optimization of truss structures. Comput Struct 2012;92-93:229-41. doi:https://doi.org/10.1016/j.compstruc.2011.10.022. 